\title{
The Association Between Web-Based or Face-to-Face Lifestyle Interventions on the Perceived Benefits and Barriers to Exercise in Midlife Women: Three-Arm Equivalency Study
}

Amanda Mary McGuire ${ }^{1}, \mathrm{PhD}$; Charrlotte Seib ${ }^{1}, \mathrm{PhD}$; Janine Porter-Steele ${ }^{1,2}$, PhD; Debra Jane Anderson ${ }^{1}, \mathrm{PhD}$

${ }^{1}$ Menzies Health Institute Queensland, Griffith University, Southport, Australia

${ }^{2}$ Wesley Hospital, Brisbane, Australia

Corresponding Author:

Amanda Mary McGuire, $\mathrm{PhD}$

Menzies Health Institute Queensland

Griffith University

Parklands Drive

Southport, 4215

Australia

Phone: 61755528860

Email: a.mcguire@griffith.edu.au

\section{Abstract}

Background: Noncommunicable diseases pose a significant threat to women's health globally, with most diseases being attributed to modifiable risk factors such as physical inactivity. Women perceive a range of benefits and barriers to exercise; however, there is little evidence about the effect of different lifestyle intervention delivery modes on perceptions of exercise.

Objective: This study aimed to compare the effect of a multiple health behavior change (MHBC) intervention called the Women's Wellness Program. This intervention was delivered in 3 different modes on perceived exercise benefits, perceived exercise barriers, and actual physical activity and exercise in midlife women.

Methods: Women aged 45 to 65 years were recruited via the study website. They were assigned in blocks to 3 different treatment groups (A: Web-based independent; B: face-to-face with nurse consultations; and C: Web-based with virtual nurse consultations). All participants received the 12-week intervention that utilizes principles from social-cognitive theory to provide a structured guide to promote healthy lifestyle behaviors with an emphasis on regular exercise and healthy eating. Data were collected using a self-report Web-based questionnaire at baseline (T1) and postintervention (T2) including perceived exercise benefits and barriers and exercise and physical activity. A data analysis examined both within- and between-group changes over time.

Results: Participants in this study $(\mathrm{N}=225)$ had a mean age of 50.9 years (SD 5.9) and most were married or living with a partner $(83.3 \%, 185 / 225)$. Attrition was $30.2 \%$ with 157 participants completing the final questionnaire. Women in all intervention groups reported a significant increase in positive perceptions of exercise $(P<.05)$; a significant increase in exercise and overall physical activity $(P<.01)$ with moderate-to-large effect sizes noted for overall physical activity $(d=0.5$ to $d=0.87)$. Participants receiving support from registered nurses in the face-to-face and Web-based groups had a greater magnitude of change in benefit perceptions and physical activity than those in the Web-based independent group. There was no significant change in exercise barrier perceptions within or between groups over time.

Conclusions: The results of this study suggest that the (MHBC) intervention is effective in increasing exercise benefit perceptions, overall physical activity, and exercise in midlife women. Although Web-based programs are cost-effective and flexible and can be delivered remotely, providing a range of options including face-to-face group delivery and personalized electronic health coaching from registered nurses has the potential to enhance participant engagement and motivation.

(J Med Internet Res 2019;21(8):e10963) doi: 10.2196/10963

\section{KEYWORDS}

exercise; physical activity; women; health behavior; behavioral medicine; health promotion; digital health; benefits and barriers 


\section{Introduction}

\section{Background}

Noncommunicable diseases (NCDs) pose a significant threat to women's health globally [1,2]. Recent estimates suggest that 4 NCDs including cardiovascular disease, cancer, respiratory disease, and type 2 diabetes account for the majority of premature deaths in women between the ages of 30 and 70 years [3]. Although it is clear that regular exercise has many physical and mental health benefits and is an important component of good health, many health promotion programs fail to adequately address the often-correlated nature of many modifiable risk factors [4]. For example, physical inactivity is often associated with other modifiable lifestyle risk factors such as an unhealthy diet, tobacco smoking, and overweight and obesity, with many adults having multiple risk factors for NCDs [4,5].

Among women, midlife is a time when the risk of developing an NCD increases [3], particularly among those who do not adhere to recommended physical activity and healthy eating guidelines [6,7] and often experience menopause-related weight gain [8,9]. Although there is no established definition of midlife, women between the ages of 40 and 65 years have normally finished childbearing and experience a physiological transition to perimenopause and menopause. Many women in this age bracket continue in paid employment with the average age that Australian women intend to retire increasing over the last decade to 64.4 years in 2017 [10]. According to Mishra et al, midlife (particularly perimenopause) is also a sensitive period when the cumulative effects of unhealthy lifestyle behaviors have a greater impact on disease risk [11]. Therefore, engaging in regular physical activity, eating a healthy diet, and maintaining a healthy body weight (body mass index [BMI] $=18.5-25.0$ ) [8] in midlife are essential to reduce risk and ensure optimal health and well-being as women age.

There is evidence that multiple health behavior change (MHBC) interventions tailored for women are effective in changing behavior [12,13]. Furthermore, given the multiple and complex role demands and stressors reported by women in this age group [14], flexible health promotion interventions have the potential to yield greater success. Over the past decade, Web-based or internet interventions also show promising results in promoting physical activity and healthy eating [15]. Moreover, though Web-based interventions targeting multiple health behaviors are fewer in number, there is evidence that they can provide an effective, flexible, cost-effective means of promoting healthy lifestyle behaviors [16-19].

Despite the potential efficacy of MHBC interventions, women perceive a range of benefits and barriers to changing exercise behavior [20-22]. Research suggests that perceived benefits of exercise include physical health and fitness, improved mental health and stress reduction, and reduced risk of illness [23-25]. Women's perception of barriers to exercise are often complex and relate to a range of personal, social, and environmental factors such as lack of time, motivation, family support and care-giving responsibilities, climate and physical safety [23-25]. Arguably, these perceptions are very important to consider when designing health promotion interventions, with evidence that benefit and barrier perceptions are correlated with actual exercise behavior change $[23,26]$. In relation to behavior change theory, the concepts of perceived benefits and perceived barriers equate to positive outcome expectations and impediments to change that influence self-efficacy beliefs as described by Bandura in the social cognitive theory [27].

\section{Women's Wellness Program Intervention}

To date, there is a paucity of evidence about how different intervention delivery modes effect benefit and barrier perceptions. In this context, the Women's Wellness Program (WWP) is a 12-week MHBC intervention designed for midlife women (Multimedia Appendix 1), targeting a range of modifiable risk factors including regular physical activity and exercise and healthy eating [12]. The original WWP that included a paper-based journal and 2 face-to-face nurse consultations was evaluated in a previous randomized controlled trial $(\mathrm{N}=90)$, finding that the intervention was effective in increasing physical activity, decreasing smoking, BMI, and weight [12]. On the basis of the social cognitive theory [27], the WWP includes detailed health education to promote health literacy and knowledge about the benefits of regular physical activity and exercise and incorporates strategies to overcome impediments/barriers to change, including realistic goal setting and health coaching to promote self-efficacy for exercise. The original Program was designed to be delivered face-to-face in a community practice setting by registered nurses trained to deliver the intervention. In this study, the WWP was revised and adapted to be delivered as a Web-based self-directed program hosted on a purpose-built website. The website also includes a separate Web portal for health consultations. Furthermore, a revised Program book was published both as an eBook and a hard copy. In this study, participants receiving health coaching received 4 nurse consultations at $0,4,8$, and 12 weeks. Results in relation to the effect of the intervention on the primary outcome measure of climacteric symptoms are reported elsewhere [28].

\section{Objectives}

This study addresses secondary outcome measures, where the effect of the WWP intervention delivered in 3 different modes/arms (Web-based independent; face-to-face with nurse consultations; and Web-based with virtual nurse consultations) on perceived exercise benefits, perceived exercise barriers, and actual physical activity and exercise in midlife women is investigated.

\section{Methods}

\section{Participants and Procedure}

Participants were Australian women aged between 40 and 65 years. Details of study participants, recruitment procedures, inclusion/exclusion criteria, and attrition are described elsewhere [28]. In short, following media publicity about the study, participants were recruited across Australia via the study website. Women with an existing diagnosis of an NCD or without computer/internet access were excluded. 


\section{Measures}

A self-report Web-based questionnaire was used to collect data from participants at baseline (T1) and postintervention (T2), including (1) sociodemographic information (T1 only), (2) perceived exercise benefits and barriers [25], (3) exercise and physical activity (Seattle Physical Activity questionnaire) [29], and (4) height $(\mathrm{cm})$ and weight $(\mathrm{kg})$. The BMI was calculated by dividing the weight in kilograms by the height in meters squared $\left(\mathrm{kg} / \mathrm{m}^{2}\right)$ [30].

This paper presents the pre- and postintervention perceived benefits and barriers measured using the Exercise Benefits and Barriers Scale (EBBS) [25]. The EBBS is a 46-item instrument using a forced response Likert-type scale. The scale contains 29 benefit items summed to calculate a total benefit subscale score $\left(\mathrm{EBBS}_{\mathrm{BEN}}\right)$, with higher scores indicating higher benefit perceptions. Benefit items are then grouped and summed to create benefit subcategories: life enhancement, physical performance, psychological outlook, social interaction, and preventive health. Example benefit items include the following: 32. Exercise improves my self-concept; 15 . Exercise increases my level of physical fitness; 2 . Exercise decreases feelings of stress and tension; 11. Exercise lets me have contact with friends and persons I enjoy; and 13. Exercise will keep me from having high blood pressure.

The 46-item scale contains 14 barrier items summed to get a total barrier subscale score $\left(\mathrm{EBBS}_{\mathrm{BAR}}\right)$, with higher scores indicating higher barrier perceptions. Barrier items are grouped and summed to create barrier subcategories: exercise milieu, time expenditure, physical exertion, and family encouragement. Example barrier items include: 9. Places for me to exercise are too far away; 4. Exercising takes too much of my time; 37. Exercise takes too much time from my family responsibilities; 6. Exercise tires me; and 33. My family members do not encourage me to exercise.

The EBBS demonstrates good reliability and internal consistency in studies that investigate exercise benefits and barriers in women [20-22]. In this study, subscale reliability was calculated with a Cronbach alpha of .94 for the benefit subscale and .87 for the barrier subscale, indicating high internal consistency.

Additional anecdotal feedback about what participants liked and disliked about the Program was obtained and invitation to make other comments was given through 3 open-ended questions asked postintervention via the Web-based questionnaire.

\section{Intervention}

The participating women completed baseline questionnaires before being assigned in blocks to one of the 3 different treatment modality groups. The 12 -week program utilizes principles from the social-cognitive theory [27] to provide participants with a structured guide to promote healthy lifestyle behaviors with an emphasis on regular physical activity and exercise, healthy eating, healthy weight, stress management, and health screening behaviors. In relation to exercise and physical activity, the intervention provides detailed evidence-based information in plain language about the current guidelines for physical activity [6]. Information about the multiple health benefits of regular physical activity (aerobic exercise, strength training, and stretching) on physical and mental health and the reducing risk of chronic disease is provided in the Program book and website and reinforced in nurse consultations. Photographic illustrations of strength exercises are provided with practical advice on starting and maintaining a regular physical activity schedule, with daily walking recommended as the starting activity for participants who are sedentary or unfit. Over the 12 weeks, participants are encouraged to gradually increase the frequency and intensity of physical activity and exercise, with Program 1 strength training exercise introduced in Week 2 and Program 2 strength exercises with dumbbells introduced in Week 5. The Program book and website include weekly activity planning with participants invited to identify and reflect on their barriers to exercise behavior change through journal activities, reflections, and discussions with a registered nurse. Participants receiving nurse consultations are supported to develop personalized goals for exercise and diet that are specific, measurable, achievable, relevant, and time bound at 0,6 , and 12 weeks.

The WWP intervention including the Program book, the Program website, and health consultations is delivered in 3 different formats: (1) Web-based independent (Arm A) had access to the WWP website that contains all of the information provided in the book and an electronic copy of the Program book only; (2) Face-to-face group supported (Arm B) included a hard copy of the Program book and 4 30- to 60-min face-to-face consultations provided by a registered nurse at 0 , 4, 8, and 12 weeks; and (3) Web-based supported (Arm C) were able to access the WWP website, download an electronic copy of the Program book, and were also provided 4 virtual consultations through a portal built into the website at $0,4,8$, and 12 weeks. Intervention fidelity was maintained through provision of structured facilitator training, through consistent record keeping and auditing, and by employing one registered nurse to deliver all consultations.

\section{Statistical Analysis}

Analyses were performed using IBM® SPPS Statistics version 22 [31]. Descriptive data are expressed as counts and percentages or mean (SD), whereas inferential statistics were performed using $t$ tests and analysis of covariance (ANCOVA) or their nonparametric equivalent. The statistical significance was set at alpha=.05. The effect size was also calculated using the Cohen $d$ standard formula [32] to examine the meaning and magnitude of change in the 3 groups over the study period. Using Cohen guidelines [32], an effect size of 0.20 was deemed to be small, an effect size of 0.50 was moderate, and an effect size of 0.80 or more was considered to be large.

\section{Ethical Approval}

Before recruitment and data collection, ethical approval was obtained from the relevant Human Research and Ethics Committee (QUT HREC Approval No: 1300000048). Participation was voluntary, and women were able to withdraw from the study at any time. Furthermore, participants did not receive any rewards or incentives for participation; however, they were able to retain the Program book and materials and have continued access to the website resources. 


\section{Results}

\section{Sociodemographic Characteristics and Baseline Body Mass Index and Physical Activity}

Participants in this study had a mean age of 50.9 years (SD 5.9) and most were married or living in a de-facto relationship $(83.3 \%, 185 / 225)$. Overall, $79.1 \%$ of women were Australian born, most worked either full- or part-time $(53.0 \%, 119 / 225$ or $29.5 \%, 66 / 225$ respectively), and almost two-thirds (68.9\%, $155 / 225)$ of participants were university educated. According to the World Health Organization categories [30], where overweight is classified as BMI 25.0 to 29.9 and obesity BMI greater than 30.0, many of the participating women reported being overweight $(35.5 \%, 79 / 225)$ or obese $(32.9 \%, 74 / 225)$. When asked about general daily activity levels (including housework, gardening, shopping, caring for children, or activity at work), the proportion of all participants at baseline who were very active was $1.8 \%$ (4/225); moderately active, $32.2 \%$ (72/225); mildly active, 46.2\% (104/225); and sedentary, $19.1 \%$ (43/225). Reported levels of aerobic exercise (15 min at a time in the past month including brisk walking, jogging, swimming, and cycling) for all women at baseline found $21.8 \%(49 / 225)$ getting no aerobic exercise; $36 \%$ (81/225) one or 2 times/week; $27.1 \%(61 / 225) 3$ or 4 times/week; $10.2 \%(23 / 225) 5$ or 6 times/week; and 4.4\% (10/225) daily exercise.
Although 225 women completed the baseline questionnaire, an attrition rate of $30.2 \%(68 / 225)$ meant that 157 women completed the final questionnaire following the 12-week intervention. A comparison of retained participants and those lost to follow-up showed significantly more participants being lost from the Web-based independent Arm A $(35.5 \%, 49 / 138)$ compared with Arm B $(9.7 \%, 4 / 41)$ and Arm C $(30.2 \%, 15 / 46)$. The comparison of baseline sociodemographic and health characteristics of the 3 intervention groups showed no significant within- or between-group differences [30].

Table 1 presents the mean total exercise benefits, barriers and benefits, and barriers subscale scores pre- and postintervention within each group. Although there was no statistically significant change in barrier scores over time, in contrast there was a significant increase in average total benefits, psychological, and social subscale scores within all 3 intervention groups. A one-way between-group ANCOVA showed no significant difference between the 3 intervention groups over time for both total exercise benefit scores $\left(F_{2,153}=0.30 ; P=.74\right.$; partial eta squared $=0.004)$ and total exercise barrier scores $\left(F_{2,153}=0.65\right.$; $P=.52$; partial eta squared $=0.01$ ). Figures 1 and 2 present the change over time in average total perceived benefit and barrier scores within and between groups.

Table 1. Mean perceived benefits and barriers to exercise scores within and between groups pre- and postintervention (N=157). Mean scores are based on an ordinal scale representing the extent to which women strongly disagree/disagree/agree/strongly agree that the item is a benefit/barrier to exercise (range 1 to 4 with high scores representing higher agreement).

\begin{tabular}{|c|c|c|c|c|c|c|}
\hline \multirow[t]{2}{*}{ Variable } & \multicolumn{2}{|c|}{$\begin{array}{l}\text { Arm A: Web-based independent } \\
(\mathrm{n}=89) \text {, mean }(\mathrm{SD})\end{array}$} & \multicolumn{2}{|c|}{$\begin{array}{l}\text { Arm B: Face-to-face supported } \\
(\mathrm{n}=37), \text { mean }(\mathrm{SD})\end{array}$} & \multicolumn{2}{|c|}{$\begin{array}{l}\text { Arm C: Web-based supported }(\mathrm{n}=31) \text {, } \\
\text { mean (SD) }\end{array}$} \\
\hline & Pre & Post & Pre & Post & Pre & Post \\
\hline \multicolumn{7}{|l|}{ Perceived benefits ${ }^{\mathrm{a}}$} \\
\hline Total benefits & $88.5(10.8)$ & $91.4(13.4)^{\mathrm{b}}$ & $91.8(9.5)$ & $95.1(14.4)^{b}$ & $91.9(11.1)$ & $93.5(10.4)^{\mathrm{b}}$ \\
\hline Life enhancement & $3.1(0.5)$ & $3.2(0.5)$ & $3.3(0.4)$ & $3.3(0.5)$ & $3.3(0.5)$ & $3.2(0.4)$ \\
\hline Physical & $3.4(0.4)$ & $3.4(0.4)$ & $3.4(0.4)$ & $3.4(0.5)$ & $3.5(0.4)$ & $3.4(0.4)$ \\
\hline Psychological & $2.9(0.4)$ & $3.2(0.5)^{\mathrm{b}}$ & $3.0(0.3)$ & $3.3(0.6)^{\mathrm{b}}$ & $3.0(0.3)$ & $3.4(0.4)^{\mathrm{b}}$ \\
\hline Social & $2.3(0.6)$ & $2.4(0.7)^{\mathrm{b}}$ & $2.5(0.6)$ & $2.7(0.7)^{b}$ & $2.5(0.6)$ & $2.5(0.5)^{\mathrm{b}}$ \\
\hline Preventive health & $3.3(0.5)$ & $3.3(0.5)$ & $3.4(0.4)$ & $3.4(0.5)$ & $3.3(0.6)$ & $3.3(0.4)$ \\
\hline \multicolumn{7}{|l|}{ Perceived barriers ${ }^{c}$} \\
\hline Total barriers & $29.6(6.1)$ & $29.0(6.9)$ & $26.9(6.5)$ & $26.1(5.3)$ & $27.3(5.6)$ & $27.1(6.2)$ \\
\hline Exercise milieu & $1.9(0.5)$ & $1.8(0.5)$ & $1.7(0.5)$ & $1.7(0.4)$ & $1.7(0.5)$ & $1.7(0.5)$ \\
\hline Time expenditure & $2.2(0.6)$ & $2.2(0.6)$ & $2.0(0.6)$ & $1.9(0.5)$ & $2.1(0.5)$ & $2.1(0.7)$ \\
\hline Physical exertion & $2.6(0.6)$ & $2.6(0.6)$ & $2.4(0.6)$ & $2.3(0.5)$ & $2.3(0.5)$ & $2.3(0.5)$ \\
\hline Family encourage & $1.8(0.7)$ & $1.9(0.9)$ & $1.7(0.8)$ & $1.7(0.7)$ & $1.7(0.5)$ & $1.7(0.5)$ \\
\hline
\end{tabular}

${ }^{\mathrm{a}}$ Exercise Benefits Subscale.

${ }^{\mathrm{b}}$ Within-group paired $t$ test; $P<.05$.

${ }^{\mathrm{c}}$ Exercise Barriers Subscale. 
Figure 1. Change over time in average perceived benefits of exercise scores within and between groups.

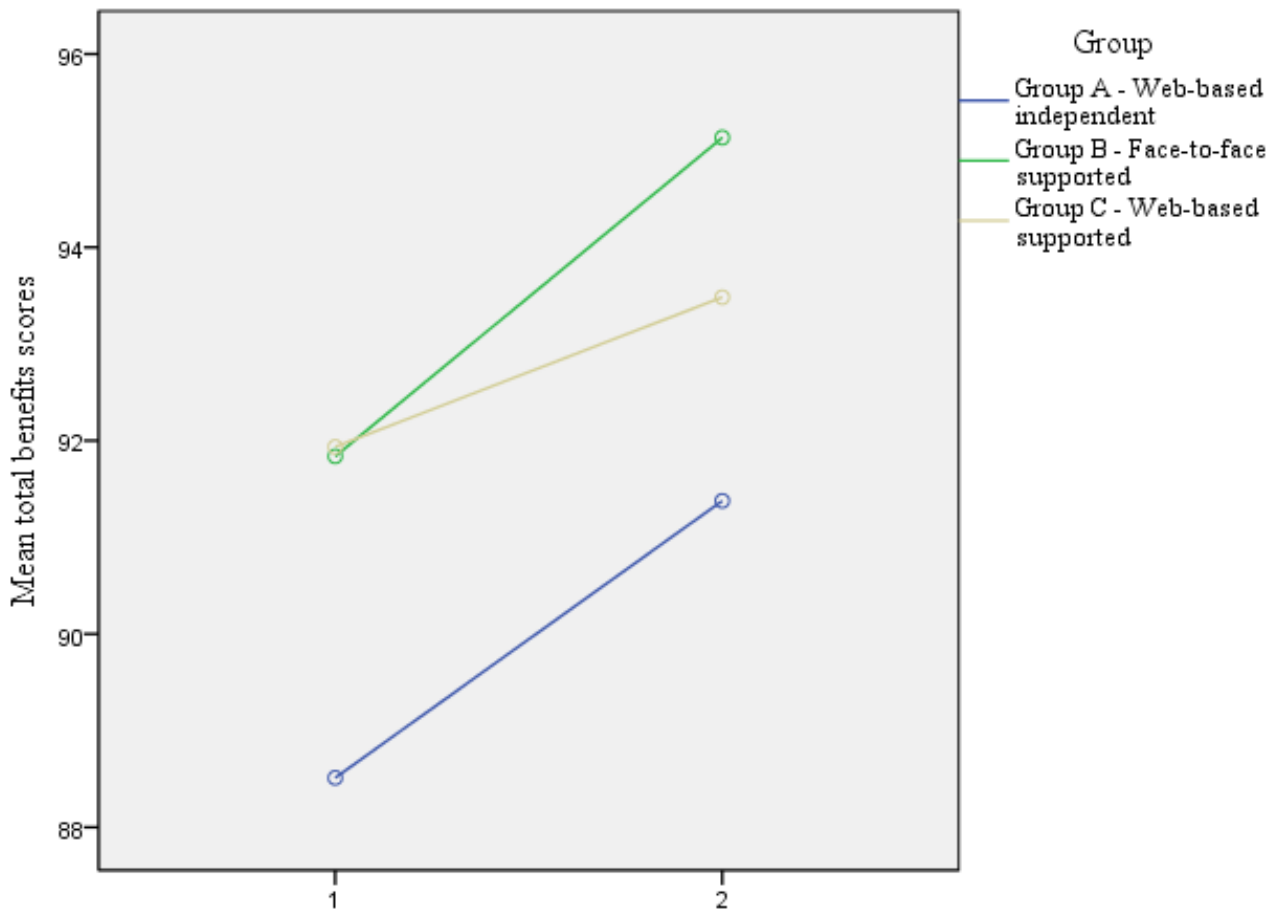

Change over time pre and post intervention

Figure 2. Change over time in average perceived barriers to exercise scores within and between groups.

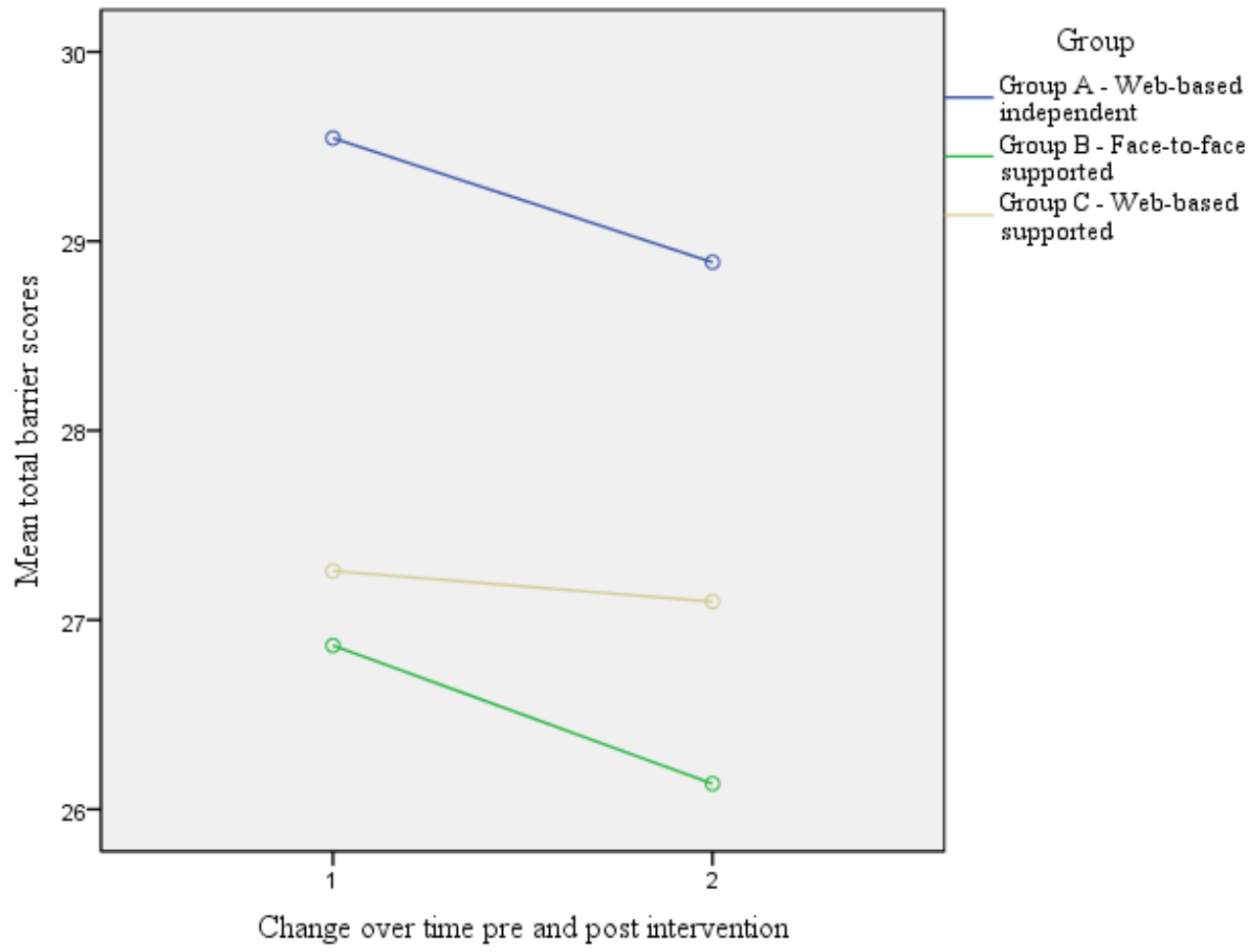

Changes in overall physical activity, aerobic exercise, and general daily activity are presented in Table 2 . There was a significant difference in all physical activity variables within all groups postintervention $(P<.01)$. Between-group comparison of overall physical activity was close to statistical significance
$\left(F_{2,148}=45.1 ; P=.052 ;\right.$ partial eta squared $\left.=0.04\right)$, with a greater increase in face-to-face supported Arm B and Web-based supported Arm C compared with Web-based independent Arm A. 
Table 2. Comparison of overall physical activity, aerobic exercise, and general daily activity within groups pre- and postintervention (N=157).

\begin{tabular}{|c|c|c|c|c|c|c|}
\hline \multirow[t]{2}{*}{ Variable } & \multicolumn{2}{|c|}{$\begin{array}{l}\text { Arm A: Web-based independent } \\
(\mathrm{n}=89)\end{array}$} & \multicolumn{2}{|c|}{$\begin{array}{l}\text { Arm B: Face-to-face supported } \\
(\mathrm{n}=37)\end{array}$} & \multicolumn{2}{|c|}{ Arm C: Web-based supported $(n=31)$} \\
\hline & Pre & Post & Pre & Post & Pre & Post \\
\hline \multicolumn{7}{|c|}{ Overall physical activity $(\mathrm{PA})^{\mathrm{a}}$} \\
\hline $\operatorname{Mean}(\mathrm{SD})^{\mathrm{b}}$ & $5.4(1.8)$ & $6.3(2.1)^{\mathrm{c}}$ & $5.8(1.9)$ & $6.9(1.9)^{\mathrm{c}}$ & $5.6(1.9)$ & $7.3(1.5)^{\mathrm{c}}$ \\
\hline Median $^{\mathrm{b}}$ & 6.0 & $7.0^{\mathrm{c}}$ & 6.0 & $8.0^{\mathrm{c}}$ & 6.0 & $8.0^{\mathrm{c}}$ \\
\hline \multicolumn{7}{|c|}{ Weekly aerobic exercise, n (\%) } \\
\hline 2 or less times weekly & $55.7(49)$ & $33.7(30)$ & $59.5(22)$ & $24.3(9)$ & $64.5(20)$ & $29.0(9)$ \\
\hline 3-4 times weekly & $31.8(28)$ & $36.0(32)$ & $21.6(8)$ & $35.1(13)$ & $25.8(8)$ & $29.0(9)$ \\
\hline $5+$ times weekly & $12.5(12)$ & $30.3(27)$ & $18.9(7)$ & $40.5(15)$ & $9.7(3)$ & $41.9(13)$ \\
\hline McNemar test & $-^{\mathrm{d}}$ & $21.3^{\mathrm{c}}$ & - & $14.3^{\mathrm{c}}$ & - & $14.5^{\mathrm{c}}$ \\
\hline \multicolumn{7}{|l|}{ General daily activity, $n(\%)$} \\
\hline Sedentary & $18.0(16)$ & $6.7(6)$ & $13.9(5)$ & $8.1(3)$ & $22.6(7)$ & $6.5(2)$ \\
\hline Mildly active & $49.4(44)$ & $36.0(32)$ & $52.8(19)$ & $29.7(11)$ & $35.5(11)$ & $22.6(7)$ \\
\hline Moderately/very active & $32.6(29)$ & $57.3(51)$ & $33.3(12)$ & $62.2(23)$ & $41.9(13)$ & $71.0(22)$ \\
\hline McNemar test & - & $25.7^{\mathrm{c}}$ & - & $9.3^{\mathrm{c}}$ & - & $8.6^{\mathrm{c}}$ \\
\hline
\end{tabular}

${ }^{a}$ Overall physical activity including exercise and general daily activity measured on a scale of 0 to 10 .

${ }^{\mathrm{b}}$ Paired $t$ test and Wilcoxon Signed Rank test.

${ }^{\mathrm{c}} P<.01$.

${ }^{\mathrm{d}}$ Not applicable.

\section{Effect Size}

Table 3 presents results of the effect size analysis within and between groups over time in perceived benefits and barriers to exercise and overall physical activity. A small effect for perceived barriers to exercise was observed, with a small-to-moderate effect for perceived benefits to exercise within all 3 groups postintervention (Cohen $\left.d_{\text {change }}\right)$. A moderate-to-large effect was seen in overall physical activity, within all intervention groups. Using Cohen $d_{2}$ to compare the difference in effect size between Arm A (Web-based independent) and Arm B (face-to-face supported) and Arm C
(Web-based supported), there was a small-to-moderate effect size observed for all variables.

To further illustrate and compare the magnitude of change over time within and between each of the 3 groups, Table 4 presents exercise benefits and barriers subscale variables and overall physical activity, grouped by effect size and study arm. Of note is the large effect size for psychological benefits in all groups and overall physical activity in the Web-based supported group C. There was a moderate effect size observed for overall physical activity in the Web-based independent (Arm A) and face-to-face supported (Arm B) groups. 
Table 3. Effect size within and between groups over time in perceived benefits and barriers to exercise and overall physical activity ( $\mathrm{N}=157)$.

\begin{tabular}{|c|c|c|c|c|c|}
\hline \multirow[t]{2}{*}{ Variables } & \multicolumn{3}{|l|}{ Cohen $d_{\text {change }}{ }^{\mathrm{a}}$} & \multicolumn{2}{|l|}{ Cohen $d_{2}{ }^{\mathrm{b}}$} \\
\hline & $\begin{array}{l}\text { Arm A: Web-based inde- } \\
\text { pendent }\end{array}$ & $\begin{array}{l}\text { Arm B: Face-to-face } \\
\text { supported }\end{array}$ & $\begin{array}{l}\text { Arm C: Web-based sup- } \\
\text { ported }\end{array}$ & A-B post & A-C post \\
\hline \multicolumn{6}{|l|}{ Perceived benefits ${ }^{c}$} \\
\hline Total benefits & 0.27 & 0.30 & 0.14 & 0.28 & 0.16 \\
\hline Life enhancement & 0.02 & 0.00 & 0.20 & 0.20 & 0.00 \\
\hline Physical & 0.00 & 0.00 & 0.25 & 0.00 & 0.00 \\
\hline Psychological & 0.70 & 1.0 & 1.3 & 0.20 & 0.40 \\
\hline Social & 0.21 & 0.33 & 0.13 & 0.43 & 0.14 \\
\hline Preventive health & 0.00 & 0.00 & 0.00 & 0.20 & 0.00 \\
\hline \multicolumn{6}{|l|}{ Perceived barriers ${ }^{d}$} \\
\hline Total barriers & 0.10 & 0.11 & 0.03 & 0.42 & 0.28 \\
\hline Exercise milieu & 0.20 & 0.00 & 0.00 & 0.01 & 0.20 \\
\hline Time expenditure & 0.00 & 0.20 & 0.00 & 0.50 & 0.20 \\
\hline Physical exertion & 0.00 & 0.20 & 0.00 & 0.50 & 0.42 \\
\hline Family encourage & -0.14 & 0.00 & 0.00 & 0.22 & 0.22 \\
\hline Overall physical activity & 0.50 & 0.60 & 0.87 & 0.31 & 0.48 \\
\hline
\end{tabular}

${ }^{\mathrm{a}}$ Cohen $d_{\text {change }}$ compared the difference in the effect size within groups over time.

${ }^{\mathrm{b}}$ Cohen $d_{2}$ compared the difference in effect size between groups postintervention.

${ }^{\mathrm{c}}$ Exercise Benefits Subscale.

${ }^{\mathrm{d}}$ Exercise Barriers Subscale.

Table 4. Comparison of magnitude of change postintervention within each group for exercise benefits and barriers subscale scores and overall physical activity.

\begin{tabular}{llll}
\hline Effect size $^{\mathrm{a}}$ & Arm A: Web-based independent & Arm B: Face-to-face supported & Arm C: Web-based supported \\
\hline Large $>.7$ & Psychological benefits & Psychological benefits & Psychological benefits; Overall PA \\
Moderate .4 to .7 & Overall PA & Overall PA & b $^{\text {b }}$ \\
Small .2 to .4 & $\begin{array}{l}\text { Total benefits score; Social benefits; } \\
\text { Exercise milieu barriers }\end{array}$ & $\begin{array}{l}\text { Social benefits; Total benefits score; } \\
\text { Time barriers; Physical exertion barri- }\end{array}$ & $\begin{array}{l}\text { Physical benefits } \\
\text { ers }\end{array}$ \\
Very small $<.2$ & Family barriers; Total barriers score; & Total barriers score & Total benefits score; Social benefits; \\
& Life enhancement benefits & & Total barriers score \\
\hline
\end{tabular}

${ }^{\mathrm{a} C o h e n} \mathrm{~d}_{\text {change }}$ compared the difference in effect size with groups over time.

${ }^{\mathrm{b}}$ Not applicable.

\section{Discussion}

\section{Principal Findings}

This study has reported the results of a 3-arm MHBC intervention on perceived exercise benefits and barriers and self-reported physical activity and exercise in midlife women. Postintervention, women in all 3 arms reported a significant increase in overall exercise benefit perceptions and increased physical activity.

With regard to exercise benefits, there was a significant change in perceptions about the psychological and social benefits in particular, with large effect sizes being noted. This change was associated with a significant increase in overall physical activity and exercise, with moderate-to-large effect sizes across all 3 groups. What is striking about these results is the proportion of participants who moved from lower levels of exercise to reporting regular exercise on 5 or more days per week postintervention. These changes in benefit perceptions and actual physical activity are likely to be a result of specific program content and strategies, including detailed health promotion information contained in the Program book, individualized goal setting, and weekly exercise planning activities undertaken by all participants over the 12 weeks of the trial. 
When comparing the magnitude of change between groups over time, the Web-based independent group (Arm A) was used as the comparison group. In comparison with the Web-based independent group, both the face-to-face supported group (Arm B) and Web-based supported group (Arm C) had greater change in benefit and barrier perceptions and overall physical activity postintervention. Women who received face-to-face support reported moderately higher social benefits, with the Web-based supported group reporting moderately higher psychological benefits. This is likely to be attributed to the additional support that Arm B and C received through nurse consultation and health coaching and the peer support available in Arm B. These results suggest that personalized and tailored health consultation provided by registered nurses with knowledge and skills in health behavior change theory and communication can facilitate positive behavior change.

In support of this, anecdotal feedback from participants indicated that having the opportunity to discuss personal health issues and work and family commitments and discuss strategies for change with a supportive health professional was highly valued by women in the face-to-face and Web-based supported groups. In contrast, feedback from participants in the Web-based independent group highlighted the lack of support being a barrier to engagement with the program, and it is likely that this contributed to the higher attrition rate in this group. However, participants in the Web-based independent group who remained in the study reported significant increases in physical activity, indicating that for some women undertaking a Web-based intervention independently is an effective option for undertaking a behavior change intervention.

Interestingly, despite a reported increase in physical activity and positive benefit perceptions, there was no statistically significant change in the average exercise barrier perceptions within or between groups postintervention. A possible explanation is that the average exercise barrier perceptions in all groups at baseline were relatively low, perhaps reflecting the fact that participants were motivated volunteers who self-selected to enroll in a health promotion program.

\section{Comparison With Previous Work}

In relation to the effect of a behavior change intervention on exercise benefit and barrier perceptions, there are limited studies to allow direct comparison. Our results are somewhat similar to a study on Latino American women that found an increase in total benefit perceptions following a 9-month biweekly education and exercise intervention [33]. In contrast, Kennedy et al [33] report a decrease in barrier perceptions. Other studies in women report no change in total benefit or barrier perceptions post exercise intervention [34,35]. One of these studies was a 7-week structured walking program designed for postmenopausal African American women [35] and the other, a 12-week group exercise program for mother and daughter pairs [34]. A more recent study investigated perceived benefits and barriers to exercise participation in $n=43$ overweight women with polycystic ovarian syndrome participating in a 3 -arm 20 -week lifestyle program, finding a significant improvement in increased benefit and decreased barrier perceptions [36]. Our study has appeared to be the first to report the effect of a 12-week MHBC intervention on exercise benefit and barrier perceptions in healthy midlife women.

There is a large body of literature in relation to the effect of Web-based physical activity interventions with our results aligning with systematic review [15] and meta-analysis [37] findings that indicate that the majority of internet PA interventions in adults lead to significant increases in physical activity. These studies both report that average effect sizes are usually small $(d=0.14)$; in contrast, our study found moderate-to-large effect sizes across all intervention groups ( $d=0.5$ to $d=0.87$, respectively). A possible explanation for these results is that the WWP intervention is specifically designed for midlife women with variable fitness levels and allows personal choice in type, intensity, and frequency of physical activity and exercise, facilitating incremental change over time. The intervention materials also explicitly address the multiple benefits of regular exercise for midlife women's health and healthy ageing and provide practical strategies for overcoming barriers to change, perhaps enhancing participant motivation to exercise. This is consistent with evidence that client-centered and personalized lifestyle interventions with ongoing support are likely to be more effective in changing behavior in both the short and medium term [38]. Results in this study are also consistent with our previous findings [12], where the original WWP was tailored for midlife women and included personalized support.

Similar to studies comparing different intervention delivery modes [39,40], our study found increases in physical activity in all groups. A similar study by Steele et al [39] investigated the effectiveness of delivery modes for a 12-week pedometer-based behavior change program (Health-e Steps), comparing face-to-face, internet-mediated, and internet-only delivery with an equivalent magnitude of increase in physical activity over time being reported. In contrast, our study found a greater magnitude of change in PA in the face-to-face and Web-based supported groups compared with the Web-based independent group. In contrast to the Web-based independent group, the face-to-face and Web-based supported groups both received health coaching including goal setting from a registered nurse. Recent systematic reviews indicate that behavioral counselling to promote PA and a healthy diet [41] and setting goals [42] are effective and important in facilitating behavior change. Building on our previous work [12], the results in this study including qualitative feedback from participants suggest that one size does not fit all. In addition to the tailored and personalized nurse-led intervention, the ability to offer women the choice of intervention delivery modes to fit their motivation levels, family and work commitments, and preferences is a positive outcome of this project.

\section{Limitations}

The results of this study need to be considered in light of the limitations. First, although women were recruited across Australia, volunteers were generally well-educated and from high-income groups. Although this is often the case for studies involving Web-based interventions with volunteers predominantly white, middle aged, and female [18], this is likely to limit the generalizability of results. In terms of attrition, 
average barrier scores were higher in the Web-based independent group (Arm A) that had the highest level of attrition (35.5\%), so data collected postintervention did not include those participants. Furthermore, this study had no control group, largely because it was designed to investigate the equivalency of the different intervention arms. Without a control group, it is difficult to definitively attribute posttest changes to the effects of the intervention. The study relied on self-report data that can be prone to response bias, with participants more likely to report positive outcomes for behavior change measures such as physical activity. Furthermore, data collection took place immediately after the intervention, so long-term effects might be lower.

\section{Conclusions}

Despite limitations, the results of this study suggest that the MHBC intervention (WWP) including personalized and tailored health coaching from registered nurses is likely to be effective in increasing exercise benefit perceptions, overall physical activity, and exercise in midlife women. The moderate-to-large effect sizes found in this study are particularly encouraging, indicating that for motivated participants, undertaking the program in different modes was beneficial in changing exercise behavior and positive perceptions of increased physical activity. Although Web-based interventions are cost-effective and flexible and can be delivered remotely, providing a range of options including face-to-face group delivery electronic health coaching from registered nurses has the potential to enhance participant engagement and motivation. With an increased focus on prevention of NCDs being evident, this study makes a timely contribution to the knowledge about exercise behavior change for prevention of NCDs in midlife women.

\section{Acknowledgments}

This study was funded by a Queensland University of Technology Bluebox Proof of Concept Grant awarded to DJA (Grant ID: WWP) and an Australian Postgraduate Award PhD Scholarship awarded to AMM. DJA and CB were PhD advisors with JP-S delivering the WWP intervention face-to-face and Web-based. All authors have been involved in preparation, review, and approval of the manuscript.

\section{Conflicts of Interest}

None declared.

\section{Multimedia Appendix 1}

Women's Wellness Program Intervention.

[PDF File (Adobe PDF File), 394KB-Multimedia Appendix 1]

\section{References}

1. GBD 2016 Risk Factor Collaborators. Global, regional, and national age-sex specific mortality for 264 causes of death, 1980-2016: a systematic analysis for the Global Burden of Disease Study 2016. The Lancet 2017 Sep 23;390(10100):1151-1210 [FREE Full text] [doi: 10.1016/S0140-6736(17)32152-9] [Medline: 28734670]

2. World Health Organization. Geneva; 2013. Global action plan for the prevention of and control of noncommunicable diseases 2013-2020 URL: https://apps.who.int/iris/bitstream/handle/10665/94384/9789241506236 eng. pdf;jsessionid=9C9891F90EF8AF16B130E04BE42AA433? sequence=1 [accessed 2018-04-01] [WebCite Cache ID 782C7wyB9]

3. Bennett JE, Stevens GA, Mathers CD, Bonita R, Rehm J, Kruk ME, et al. NCD Countdown 2030: worldwide trends in non-communicable disease mortality and progress towards Sustainable Development Goal target 3.4. Lancet 2018 Sep;392(10152):1072-1088. [doi: 10.1016/S0140-6736(18)31992-5]

4. GBD 2015 Risk Factors Collaborators. Global, regional, and national comparative risk assessment of 79 behavioural, environmental and occupational, and metabolic risks or clusters of risks, 1990-2015: a systematic analysis for the Global Burden of Disease Study 2015. Lancet 2016 Oct 8;388(10053):1659-1724 [FREE Full text] [doi: 10.1016/S0140-6736(16)31679-8] [Medline: 27733284]

5. Australian Institute of Health and Welfare. Canberra; 2018. Australia's Health 2018, in Australia's health series no 16 URL: https://www.aihw.gov.au/getmedia/7c42913d-295f-4bc9-9c24-4e44eff4a04a/aihw-aus-221.pdf.aspx?inline=true [accessed 2019-05-01] [WebCite Cache ID 782DWWafr]

6. Australian Government Department of Health. Australian Government Department of Health. Canberra: Commonwealth of Australia; 2014. Australian Physical Activity and Sedentary Behaviour Guidelines for Adults 18-64 years URL: http:/ /www.health.gov.au/internet/main/publishing.nsf/Content/health-pubhlth-strateg-phys-act-guidelines [accessed 2019-04-30] [WebCite Cache ID 782E7HNRZ]

7. National Health and Medical Research Council. Canberra: NHMRC; 2013. Australian Dietary Guidlelines URL: https:/ /www.nhmrc.gov.au/about-us/publications/australian-dietary-guidelines [accessed 2019-04-30] [WebCite Cache ID 782ETRszf] 
8. Nejat EJ, Polotsky AJ, Pal L. Predictors of chronic disease at midlife and beyond-the health risks of obesity. Maturitas 2010 Feb;65(2):106-111. [doi: 10.1016/j.maturitas.2009.09.006] [Medline: 19796885]

9. Sun Q, Townsend MK, Okereke OI, Franco OH, Hu FB, Grodstein F. Adiposity and weight change in mid-life in relation to healthy survival after age 70 in women: prospective cohort study. Br Med J 2009 Sep 29;339:b3796 [FREE Full text] [Medline: 19789407]

10. Australian Bureau of Statistics. Canberra: ABS; 2017. Retirement and Retirement Intentions, Australia, July 2016 to June 2017 URL: https://www.abs.gov.au/ausstats/abs@.nsf/mf/6238.0 [accessed 2019-04-30] [WebCite Cache ID 782EsqUvv]

11. Mishra GD, Cooper R, Kuh D. A life course approach to reproductive health: theory and methods. Maturitas 2010 Feb;65(2):92-97 [FREE Full text] [doi: 10.1016/j.maturitas.2009.12.009] [Medline: 20079587]

12. Anderson D, Mizzari K, Kain V, Webster J. The effects of a multimodal intervention trial to promote lifestyle factors associated with the prevention of cardiovascular disease in menopausal and postmenopausal Australian women. Health Care Women Int 2006 Mar;27(3):238-253. [doi: 10.1080/07399330500506543] [Medline: 16524854]

13. Keyserling TC, Samuel Hodge CD, Jilcott SB, Johnston LF, Garcia BA, Gizlice Z, et al. Randomized trial of a clinic-based, community-supported, lifestyle intervention to improve physical activity and diet: the North Carolina enhanced WISEWOMAN project. Prev Med 2008 Jun;46(6):499-510. [doi: 10.1016/j.ypmed.2008.02.011] [Medline: 18394692]

14. Darling CA, Coccia C, Senatore N. Women in midlife: stress, health and life satisfaction. Stress Health 2012 Feb;28(1):31-40. [doi: 10.1002/smi.1398] [Medline: 22259156]

15. Joseph RP, Durant NH, Benitez TJ, Pekmezi DW. Internet-based physical activity interventions. Am J Lifestyle Med 2014 Dec;8(1):42-68 [FREE Full text] [doi: 10.1177/1559827613498059] [Medline: 25045343]

16. Duan YP, Wienert J, Hu C, Si GY, Lippke S. Web-based intervention for physical activity and fruit and vegetable intake among Chinese university students: a randomized controlled trial. J Med Internet Res 2017 Apr 10;19(4):e106 [FREE Full text] [doi: 10.2196/jmir.7152] [Medline: 28396306]

17. Schulz DN, Kremers SP, Vandelanotte C, van Adrichem MJ, Schneider F, Candel MJJM, et al. Effects of a web-based tailored multiple-lifestyle intervention for adults: a two-year randomized controlled trial comparing sequential and simultaneous delivery modes. J Med Internet Res 2014 Jan;16(1):e26 [FREE Full text] [doi: 10.2196/jmir.3094] [Medline: 24472854]

18. Spring B, Pellegrini C, McFadden HG, Pfammatter AF, Stump TK, Siddique J, et al. Multicomponent mHealth intervention for large, sustained change in multiple diet and activity risk behaviors: the make better choices 2 randomized controlled Trial. J Med Internet Res 2018 Jun 19;20(6):e10528 [FREE Full text] [doi: 10.2196/10528] [Medline: 29921561]

19. Storm V, Dörenkämper J, Reinwand DA, Wienert J, de Vries H, Lippke S. Effectiveness of a web-based computer-tailored multiple-lifestyle intervention for people interested in reducing their cardiovascular risk: a randomized controlled trial. $\mathrm{J}$ Med Internet Res 2016 Apr 11;18(4):e78 [FREE Full text] [doi: 10.2196/jmir.5147] [Medline: 27068880]

20. Adams M, McCrone S. Predictors of exercise in midline and older women based on the health promotion model. Women Sport Phys Act J 2011 Oct;20(2):65-75. [doi: 10.1123/wspaj.20.2.65]

21. Gatewood JG, Litchfield RE, Ryan SJ, Geadelmann JD, Pendergast JF, Ullom KK. Perceived barriers to community-based health promotion program participation. Am J Health Behav 2008;32(3):260-271. [doi: 10.5555/ajhb.2008.32.3.260] [Medline: 18067466 ]

22. Lovell GP, El Ansari W, Parker JK. Perceived exercise benefits and barriers of non-exercising female university students in the United Kingdom. Int J Environ Res Public Health 2010 Dec;7(3):784-798 [FREE Full text] [doi: 10.3390/ijerph7030784] [Medline: 20617003]

23. McGuire A, Seib C, Anderson D. Factors predicting barriers to exercise in midlife Australian women. Maturitas 2016 May;87:61-66. [doi: 10.1016/j.maturitas.2016.02.010] [Medline: 27013289]

24. McGuire AM, Anderson DJ, Fulbrook P. Perceived barriers to healthy lifestyle activities in midlife and older Australian women with type 2 diabetes. Collegian 2014;21(4):301-310. [Medline: 25632727]

25. Sechrist KR, Walker SN, Pender NJ. Development and psychometric evaluation of the exercise benefits/barriers scale. Res Nurs Health 1987 Dec;10(6):357-365. [doi: 10.1002/nur.4770100603] [Medline: 3423307]

26. Gho SA, Munro BJ, Jones SC, Steele JR. Perceived exercise barriers explain exercise participation in Australian women treated for breast cancer better than perceived exercise benefits. Phys Ther 2014 Dec;94(12):1765-1774. [doi: 10.2522/ptj.20130473] [Medline: 25060956]

27. Bandura A. Health promotion by social cognitive means. Health Educ Behav 2004 Apr;31(2):143-164. [doi: 10.1177/1090198104263660] [Medline: 15090118]

28. Anderson D, Seib C, McGuire A, Porter-Steele J. Decreasing menopausal symptoms in women undertaking a web-based multi-modal lifestyle intervention: the Women's Wellness Program. Maturitas 2015 May;81(1):69-75. [doi: 10.1016/j.maturitas.2015.02.263] [Medline: 25818771]

29. Woods NF, Mitchell ES. Sleep symptoms during the menopausal transition and early postmenopause: observations from the Seattle Midlife Women's Health Study. Sleep 2010 Apr;33(4):539-549 [FREE Full text] [Medline: 20394324]

30. World Health Organization. Geneva: WHO; 2018. Obesity and overweight URL: http://www.who.int/news-room/fact-sheets/ detail/obesity-and-overweight [accessed 2018-03-01] [WebCite Cache ID 782FhJCnz] 
31. IBM. Chicago: IBM; 2013. Statistical Package for Social Sciences URL: https://www.ibm.com/au-en/analytics/ spss-statistics-software [accessed 2019-05-01] [WebCite Cache ID 782GGnFm5]

32. Cohen JW. Statistical Power Analysis for the Behavioural Sciences. Hillsdale, NJ: Lawrence Erlbaum Associates; 1988.

33. Kennedy C, Devoe D, Skov J, Short-Degraff M. Attitudinal changes toward exercise in mexican american women. Occup Ther Health Care 1998;11(3):17-28. [doi: 10.1080/J003v11n03 02] [Medline: 23948043]

34. Ransdell LB, Detling N, Hildebrand K, Lau P. Can physical activity interventions change perceved exercise benefits and barriers? Am J Health Stud 2004;19(4):195-204 https://scholarworks.boisestate.edu/kinesiology_facpubs/81/.

35. Williams BR, Bezner J, Chesbro SB, Leavitt R. The effect of a walking program on perceived benefits and barriers to exercise in postmenopausal African American women. J Geriatr Phys Ther 2006;29(2):43-49. [Medline: 16914065]

36. Thomson RL, Buckley JD, Brinkworth GD. Perceived exercise barriers are reduced and benefits are improved with lifestyle modification in overweight and obese women with polycystic ovary syndrome: a randomised controlled trial. BMC Womens Health 2016 Mar 9;16:14 [FREE Full text] [doi: 10.1186/s12905-016-0292-8] [Medline: 26960762]

37. Davies CA, Spence JC, Vandelanotte C, Caperchione CM, Mummery WK. Meta-analysis of internet-delivered interventions to increase physical activity levels. Int J Behav Nutr Phys Act 2012 Apr 30;9:52 [FREE Full text] [doi: 10.1186/1479-5868-9-52] [Medline: 22546283]

38. Zubala A, MacGillivray S, Frost H, Kroll T, Skelton DA, Gavine A, et al. Promotion of physical activity interventions for community dwelling older adults: a systematic review of reviews. PLoS One 2017;12(7):e0180902 [FREE Full text] [doi: 10.1371/journal.pone.0180902] [Medline: 28700754]

39. Steele R, Mummery WK, Dwyer T. Using the internet to promote physical activity: a randomized trial of intervention delivery modes. J Phys Act Health 2007 Jul;4(3):245-260. [Medline: 17846455]

40. Vandelanotte C, Duncan MJ, Plotnikoff RC, Mummery WK. Do participants' preferences for mode of delivery (text, video, or both) influence the effectiveness of a Web-based physical activity intervention? J Med Internet Res 2012 Feb 29;14(1):e37 [FREE Full text] [doi: 10.2196/jmir.1998] [Medline: 22377834]

41. Patnode CD, Evans CV, Senger CA, Redmond N, Lin JS. Behavioral counseling to promote a healthful diet and physical activity for cardiovascular disease prevention in adults without known cardiovascular disease risk factors: Updated evidence report and systematic review for the US Preventive Services Task Force. J Am Med Assoc 2017 Jul 11;318(2):175-193. [doi: 10.1001/jama.2017.3303] [Medline: 28697259]

42. Epton T, Currie S, Armitage CJ. Unique effects of setting goals on behavior change: systematic review and meta-analysis. J Consult Clin Psychol 2017 Dec;85(12):1182-1198. [doi: 10.1037/ccp0000260] [Medline: 29189034]

\section{Abbreviations}

ANCOVA: analysis of covariance

BMI: body mass index

EBBS: Exercise Benefits and Barriers Scale

MHBC: multiple health behavior change

NCD: noncommunicable disease

WWP: Women's Wellness Program

Edited by G Eysenbach; submitted 04.05.18; peer-reviewed by S Lippke, D Reinwand; comments to author 03.09.18; revised version
received 19.11.18; accepted 30.03.19; published 21.08 .19
Please cite as:
McGuire AM, Seib C, Porter-Steele J, Anderson DJ
The Association Between Web-Based or Face-to-Face Lifestyle Interventions on the Perceived Benefits and Barriers to Exercise in
Midlife Women: Three-Arm Equivalency Study
J Med Internet Res $2019 ; 21(8):$ e10963
URL: $\underline{\text { https://www.jmir.org/2019/8/e10963/ }}$
doi: $\underline{10.2196 / 10963}$
PMID: $\underline{31436162}$

(C)Amanda Mary McGuire, Charrlotte Seib, Janine Porter-Steele, Debra Jane Anderson. Originally published in the Journal of Medical Internet Research (http://www.jmir.org), 21.08.2019. This is an open-access article distributed under the terms of the Creative Commons Attribution License (https://creativecommons.org/licenses/by/4.0/), which permits unrestricted use, distribution, and reproduction in any medium, provided the original work, first published in the Journal of Medical Internet Research, is properly cited. The complete bibliographic information, a link to the original publication on http://www.jmir.org/, as well as this copyright and license information must be included. 